OPEN ACCESS

Edited by:

Regie Santos-Cortez, University of Colorado, United States

Reviewed by:

Lena Hafren,

University of Helsinki, Finland

Gijs Van Ingen,

Erasmus Medical Center, Netherlands

*Correspondence:

Arnaud P. J. Giese

agiese@som.umaryland.edu

Zubair M. Ahmed

zmahmed@som.umaryland.edu

${ }^{\dagger}$ These authors have contributed equally to this work

Specialty section:

This article was submitted to

Genetic Disorders,

a section of the journal

Frontiers in Genetics

Received: 05 September 2019

Accepted: 16 March 2020

Published: 23 April 2020

Citation:

Giese APJ, Ali S, Isaiah A, Aziz I, Riazuddin S and Ahmed ZM (2020)

Genomics of Otitis Media (OM):

Molecular Genetics Approaches

to Characterize Disease

Pathophysiology.

Front. Genet. 11:313.

doi: 10.3389/fgene.2020.00313

\section{Genomics of Otitis Media (OM): Molecular Genetics Approaches to Characterize Disease Pathophysiology}

\author{
Arnaud P. J. Giese ${ }^{1 *}$, Saadat Ali ${ }^{2 \dagger}$, Amal Isaiah ${ }^{1}$, Ishrat Aziz ${ }^{3}$, Saima Riazuddin ${ }^{1}$ and \\ Zubair M. Ahmed ${ }^{1 *}$
}

1 Department of Otorhinolaryngology - Head and Neck Surgery, University of Maryland School of Medicine, Baltimore, MD, United States, ${ }^{2}$ The Institute of Biochemistry and Biotechnology, University of Veterinary and Animal Sciences, Lahore, Pakistan, ${ }^{3}$ Department of Biotechnology, Virtual University of Pakistan, Lahore, Pakistan

Otitis media $(\mathrm{OM})$ is an infective and inflammatory disorder known to be a major cause of hearing impairment across all age groups. Both acute and chronic OM result in substantial healthcare utilization related to antibiotic prescription and surgical procedures necessary for its management. Although several studies provided evidence of genetics playing a significant role in the susceptibility to OM, we had limited knowledge about the genes associated with OM until recently. Here we have summarized the known genetic factors that confer susceptibility to various forms of OM in mice and in humans and their genetic load, along with associated cellular signaling pathways. Spotlighted in this review are fucosyltransferase (FUT) enzymes, which have been implicated in the pathogenesis of OM. A comprehensive understanding of the functions of OM-associated genes may provide potential opportunities for its diagnosis and treatment.

Keywords: otitis media (OM), omic, genetic, FUT, fucosyltransferase, A2ML1

\section{INTRODUCTION}

Otitis media (OM) is defined as an infective and inflammatory disorder of the middle ear. While $\mathrm{OM}$ is associated with significant heterogeneity in clinical presentation, the broad types include acute otitis media (AOM), chronic suppurative otitis media (CSOM), and chronic otitis media with effusion (OME). Previous studies have shown that the pooled incidence of AOM is about $11 \%$ worldwide, with $51 \%$ of cases occurring in children under the age of five (Monasta et al., 2012). The recurrence of AOM may lead to OME, which has a worldwide incidence rate of up to $5 \%$ (Monasta et al., 2012). Both AOM and OM continue to be associated with healthcare utilization in the form of antibiotic therapy, physician and emergency room visits, and common surgical procedures such as tympanostomy tubes, although the advent of effective antimicrobial therapy has led to a substantial reduction in the burden of CSOM (Thomas et al., 2004). A smaller number of studies have also described an association between middle ear infections and speech and language deficits, emphasizing the role of OM in childhood development (Roberts et al., 2004).

The most common bacteria isolated from the middle ear of patients with AOM include Streptococcus pneumoniae and Haemophilus influenzae, although Moraxella catarrhalis, 
Streptococcus pyogenes, and Staphylococcus aureus are less frequently observed. In contrast, Pseudomonas aeruginosa and $S$. aureus are the most frequently observed pathogens in CSOM (Giebink and Canafax, 1991).

$\mathrm{OM}$ is a multifactorial disorder that may be attributed to a combination of etiologic factors including immunologic, genetic, environmental, and anatomic characteristics. Seasonal microbial susceptibility and Eustachian tube dysfunction are the commonly observed causes (Swanson and Hoecker, 1996; Fireman, 1997). It is well-known that viruses from the respiratory airways also play a crucial role in the pathogenesis of AOM (Nokso-Koivisto et al., 2015). Further, exposure to tobacco smoke, the use of a pacifier, and daycare attendance are among the risk factors for OM, while breastfeeding and pneumococcal vaccines have protective effects (Swanson and Hoecker, 1996; Lubianca Neto et al., 2006; Abrahams and Labbok, 2011; Norhayati et al., 2017).

Beyond environmental factors, genetic background also confers susceptibility to OM, although the disease mechanism is not fully understood. Several OM-associated genes, identified through studies in humans and in animal models, are known to play fundamental roles in diverse biological processes including (1) the development of the middle ear cleft and the Eustachian tube, (2) immune response, (3) bacterial adhesion and viral infection rate, (4) regulation of extracellular matrix, and (5) clearance of pathogens (see Tables 1, 2 for specific studies). In this review, we summarized the genomic variants and factors that have been reported in patients with various forms of OM. Early genetic association studies, mouse, mouse-to-man, human candidate, and genome-wide association studies that correlate $\mathrm{OM}$ and genetic variations are also briefly discussed. However, we particularly focused on the recent findings of the associations of A2ML1 and FUT enzymes with OM and offered our perspective on the potential disease mechanism that intuitively can lead to $\mathrm{OM}$ in individuals harboring variants of FUT2.

\section{Early Studies}

The genetic contribution to OM susceptibility became evident in the 1980s after several studies showed that the prevalence of OM was disproportionately high in some ethnicities (native Americans and Australian aborigines) and relatively low in individuals of African ancestry (Clements, 1968; Bhutta, 2015). A surveillance study on ear and nasopharyngeal carriage was conducted among remote Australian aboriginal communities in 2013 and found that $50 \%$ of young children (mean age 13 months) had OME, 37\% had AOM, and 12\% had CSOM (Leach et al., 2016). Today, CSOM continues to be strongly implicated in the prevalence of hearing and learning disorders in Australian aboriginal communities (Morris, 1998).

One of the earliest genetic studies on OM, conducted in 1983, analyzed the blood groups (ABO) in a cohort of 610 children with chronic otitis media with effusion (COME) and concluded that blood group " $A$ " was a genetic risk factor for OM based on their observation of its higher prevalence in children with COME as compared to non-affected children (Mortensen et al., 1983). Later studies have shown that human leukocyte antigen (HLA) 2 and HLA3 are strongly associated with AOM, while patients with COME have a lower frequency of HLA2 (Kalm et al., 1991, 1994).
The heritability and genetic components of time with and the number of episodes with OME and AOM during the first 2 years of life were also investigated in a twin and a triplet study in 1999 and found a strong association between the duration or the number of episodes of $\mathrm{OM}$ and genetic makeup (Casselbrant et al., 1999).

The contribution of genetics to OM susceptibility is supported by studies reporting a higher incidence of $\mathrm{OM}$ in children with chromosomal abnormalities. For example, the prevalence of OME in children with Down syndrome approaches 38\% (Austeng et al., 2013). Genes present on chromosome 21 in combination with craniofacial defects such as midfacial hypoplasia, short palate, and Eustachian tube dysfunction (Shibahara and Sando, 1989) and defects of the immune system (Ram and Chinen, 2011) observed in children with Down syndrome may contribute to their increased risk of OM. Ets1 gene, encoding a proto-oncogene, has been recently associated with craniofacial abnormalities and $\mathrm{OM}$ in a mouse study (see section Mouse and Mouse-to-Man Studies) (Carpinelli et al., 2015). In humans, the ETS2 gene that also belongs to the protooncogene gene family is present on chromosome 21 and may contribute to OM susceptibility in Down syndrome.

Several studies conducted on cohorts with Turner syndrome, a genetic disorder of partial or complete loss of chromosome $\mathrm{X}$ in females, described a highly variable (ranging from 9.1 to 91\%) incidence of AOM (Sculerati et al., 1990; Bois et al., 2018). While the karyotype analysis did not reveal any significantly high-risk subgroup, females with Turner syndrome also have greater prevalence and longer duration of middle ear pathologies (Gawron et al., 2008; Bois et al., 2018). These findings implicate some of the $\mathrm{X}$ chromosome genes in middle ear development, function, or health.

\section{Mouse and Mouse-to-Man Studies}

The development and the phenotyping of transgenic and knockout mouse models in the last 30 years have significantly helped to identify several genes and genetic variations that confer susceptibility to OM in mice. Most of these mouse models spontaneously develop OM; studying their ear morphology and function provided insights into the disease pathophysiology at a molecular level. For instance, Eriksson et al. (2006) showed that plasminogen $(\mathrm{Plg})$-deficient mice spontaneously develop chronic OM by 18 weeks of age. Plasmin, the active serine proteinase enzyme form of PLG, is mainly involved in the dissociation of fibrin clots and promotes the degradation of the extracellular matrix (Ayon-Nunez et al., 2018). Plasmin plays a critical role in several cellular processes, including wound healing, immunity, tissue remodeling, inflammation, and cell migration (Tefs et al., 2006). Recent studies have shown that certain bacteria possess plasminogen-binding adhesions on their cell surface to exploit the fibrinolytic system, facilitating bacterial uptake and invasion (Raymond and Djordjevic, 2015; Ayon-Nunez et al., 2018).

The role of transcription factors in OM pathology became apparent through the studies of mutant mice lacking Eya4, Evi1, Tgif, Ets1, and Fli1 genes (Hardisty-Hughes et al., 2006; Parkinson et al., 2006; Depreux et al., 2008; Tateossian et al., 2013; Carpinelli et al., 2015). Mice lacking Eya4 have Eustachian 
TABLE 1 | Most common loci associated with otitis media in mouse studies.

\begin{tabular}{|c|c|c|c|c|}
\hline Locus & Protein & Protein function/phenotype in mouse mutant & OMIM & References \\
\hline $\mathrm{C} 3 \mathrm{H} / \mathrm{Hej}$ & TLR4 mice strain & TLR4 mice are prone to bacterial infection & 603030 & Mitchell et al., 1997 \\
\hline Cc/3 & C-C motif chemokine 3 & Downstream of TNF-mediated inflammation pathways & 182283 & Leichtle et al., 2010 \\
\hline$C f b$ & Complement factor B & $\begin{array}{l}\text { Streptococcus pneumoniae induced increased gene expression of factor B of the } \\
\text { alternative complement pathway and C3 in mouse middle ear epithelium }\end{array}$ & 138470 & Li et al., 2011 \\
\hline Chd7 7 & Chromodomain-helicase-DNA-binding protein 7 & OM with effusion & 608892 & Tian et al., 2012 \\
\hline Eda & Ectodysplasin-A & Otitis media, rhinitis, and nasopharyngitis & 300451 & Azar et al., 2016 \\
\hline Edar & $\begin{array}{l}\text { Tumor necrosis factor receptor superfamily member } \\
\text { EDAR }\end{array}$ & Otitis media, rhinitis, and nasopharyngitis & 604095 & Azar et al., 2016 \\
\hline Enpp1 & $\begin{array}{l}\text { Ectonucleotide } \\
\text { pyrophosphatase/phosphodiesterase family } \\
\text { member } 1\end{array}$ & OM with effusion in Enpp $1^{\text {asj }}$ mutant mice & 173335 & Tian et al., 2016 \\
\hline Ets1 & E26 transformation-specific 1 & $\begin{array}{l}\text { Craniofacial abnormalities, small middle ear cavity, short nasal bone, hearing impairment, } \\
\text { otitis media, fusion of ossicles to the middle ear wall, and deformed stapes }\end{array}$ & 164720 & Carpinelli et al., 2015 \\
\hline Evi1 & Ectotropic viral integration 1 & Chronic suppurative OM with otorrhea & 165215 & Parkinson et al., 2006 \\
\hline Eya4 & Eyes absent homolog 4 & Abnormal middle ear cavity and Eustachian tube & 603550 & Depreux et al., 2008 \\
\hline Fbxo11 & F-box only protein 11 & $\begin{array}{l}\text { Compound heterozygotes carrying both Jeff and Mutt alleles demonstrated a shortened } \\
\text { face, reduced hearing, and OM }\end{array}$ & 607871 & Hardisty-Hughes et al., 2006 \\
\hline Fli1 & Friend leukemia integration 1 transcription factor & $\begin{array}{l}\text { Craniofacial abnormalities, small middle ear cavity, short nasal bone, hearing impairment, } \\
\text { otitis media, fusion of ossicles to the middle ear wall, and deformed stapes }\end{array}$ & 193067 & Carpinelli et al., 2015 \\
\hline Hbegf & Heparin binding EGF- like growth factor & Mucosal epithelial hyperplasia & 126150 & Suzukawa et al., 2014 \\
\hline Hif & Hypoxia inducible factor & Hypoxia and signal abruptions & 603348 & Cheeseman et al., 2011 \\
\hline Jnk1 & JNK1 & C57BL/6 mice deficient in JNK1 exhibit enhanced mucosal thickening & 601158 & Yao et al., 2014 \\
\hline Jnk2 & JNK2 & $\begin{array}{l}\text { JNK2-/- mice exhibit delayed mucosal hyperplasia, delayed recruitment of neutrophils, and } \\
\text { failure of bacterial clearance }\end{array}$ & 602896 & Yao et al., 2014 \\
\hline Lysozyme M & Lysozyme M & $\begin{array}{l}\text { Lysozyme M deficiency leads to an increased susceptibility to Streptococcus } \\
\text { pneumoniae-induced OM }\end{array}$ & 153450 & Shimada et al., 2008 \\
\hline Lmna & Prelamin-A/C & $\begin{array}{l}\text { Malformation and abnormal positioning of the Eustachian tube, accompanied by OM, were } \\
\text { observed in all of the Lmna(Dhe/+) mutant mice }\end{array}$ & 150330 & Zhang et al., 2012 \\
\hline MyD88 & $\begin{array}{l}\text { Myeloid differentiation primary response protein } \\
\text { MyD88 }\end{array}$ & Delayed recruitment of neutrophils and macrophages & 602170 & Hernandez et al., 2008 \\
\hline Mcp 1/Ccl2 & C-C motif chemokine 2 & MCP-1/CCL2 contributes to inner ear inflammation secondary to NTHi -induced OM & 158105 & Woo et al., 2010 \\
\hline Math1 & Protein atonal homolog 1 & Important for mucous cell differentiation & 601461 & Nakamura et al., 2013 \\
\hline Mph1 & Sex comb of midleg & OM with effusion in the hearing-impaired Mcph1(tm1a) (/tm1a) mutant mice & 300227 & Chen et al., 2013 \\
\hline
\end{tabular}




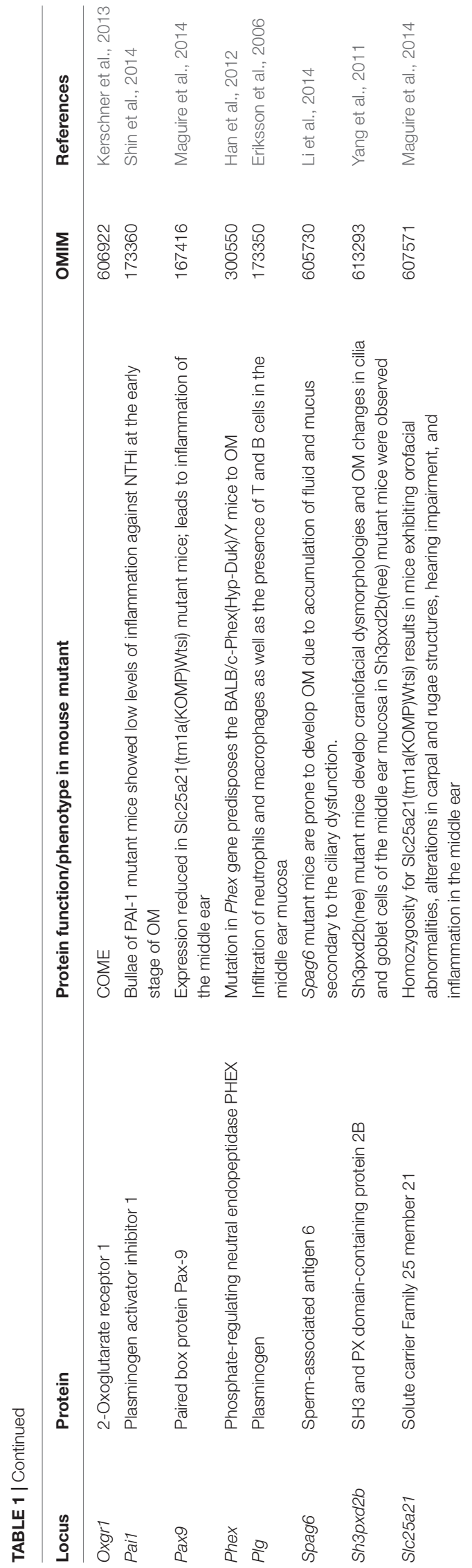

tube dysfunction, leading to an increased incidence of OME and hearing impairment (Depreux et al., 2008). Variants in Evil in Junbo mice have been shown to cause susceptibility to CSOM. Junbo mice accumulate middle ear effusions and develop hypoxia, inflammation, and thickening of the mucoperiosteum (Parkinson et al., 2006; Bhutta et al., 2014). Later studies have shown that the loss of BPIFA1, one of the most abundant secretory proteins in the upper respiratory tract (Musa et al., 2012), exacerbates the severity of OM in Junbo mice. While Bpifa1 mutant mice did not show any OM susceptibility, the deletion of Bpifa1 in mice carrying Evil Junbo variant leads to the thickening of the middle ear mucosa and an increase of collagen deposition (Mulay et al., 2018). Loss of Tgif1, which encodes for TGIF1, results in OME accompanied by the thickening of the middle ear epithelial lining, an increase of goblet cell population, elevated levels of TNF$\alpha$ and IL-1 $\beta$ in ear fluids, and conductive hearing loss in mice (Tateossian et al., 2013). Similarly, haploinsufficiency for Ets1 and Fli1 in mice results in craniofacial abnormalities, including a smaller middle ear cavity and fusion of ossicles to the walls of the middle ear (Carpinelli et al., 2015). Furthermore, Fli1 ${ }^{ \pm}$and Ets $1^{ \pm}$ double-mutant mice have hearing impairment and their middle ear mucosa is infiltrated by proinflammatory cells, leading to OM (Carpinelli et al., 2015).

Hardisty et al. (2003) showed that Jeff mutant mice carrying a Fbxo11 variant have craniofacial abnormalities, elevated hearing thresholds, and middle ear effusion. Defects in the bulla cavitation were observed in Fbxo11 mutant mice, which ultimately result in middle ear adhesions and soft tissue mineralization of the bony anatomy (Del-Pozo et al., 2019). Using $\mathrm{N}$-ethyl-N-nitrosourea mutagenesis, Crompton et al. (2017) showed that the pathogenic variant, p.Leu972Pro, also known as edison variant, in the Nischarin (Nisch) gene leads to mild craniofacial defects, spontaneous $\mathrm{OM}$ by 20 weeks, and progressive hearing loss. Recent studies have reported the association of TGIF1 and NISCH loci as potential risk areas for OM in humans (Bhutta et al., 2017), thus supporting the relevance of knowledge obtained from mouse models to the pathophysiology of OM in humans.

Finally, Eda and Edar transcription factors mutant mice $\left(E d a^{T a}\right.$ and $\left.E d a r^{d l J} / d l J\right)$ also developed chronic rhinitis and OM (Azar et al., 2016). In these mutants, the nasopharyngeal glandular epithelium fails to develop, which leads to the loss of lysozyme secretion, the reduction of mucociliary clearance, and the overgrowth of commensal bacteria. The spread of nasal

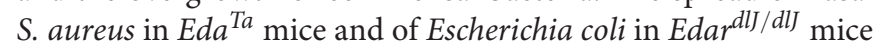
into the middle ear bulla potentially triggers inflammation and OM (Azar et al., 2016). A non-exhaustive list of the most common loci associated with OM in mouse is presented in Table 1.

\section{Human Candidate Gene-Based and Genome-Wide Association Studies}

While early candidate gene-based $\mathrm{OM}$ studies have been done mostly on Caucasian patients with recurrent AOM and chronic OME (see section Early Studies), more recent genetic studies have been focusing on ethnic groups or communities for which marriages within the families are 
TABLE 2 | Most common loci associated with otitis media in human studies.

\begin{tabular}{|c|c|c|c|c|c|c|c|c|c|}
\hline Gene & Chr: & Protein & $\begin{array}{l}\text { Function/ } \\
\text { pathway }\end{array}$ & Marker & Country & Sample size & Significance & Clinical outcome & References \\
\hline A2ML1 & 12 & $\begin{array}{l}\text { Alpha-2- } \\
\text { macroglobulin-like } \\
\text { protein } 1 \text { (A2ML1) }\end{array}$ & $\begin{array}{l}\text { Peptidase } \\
\text { inhibitor activity }\end{array}$ & $\begin{array}{l}\text { c.2478_2485dupGG } \\
\text { CTAAAT } \\
\text { (p.Ser829Trpfs*9), } \\
\text { p.Glu972 }{ }^{\star}\end{array}$ & Philippines & $\begin{array}{l}\text { Familial } \\
\text { (affected = 38, } \\
\text { unaffected = 13) }\end{array}$ & $\mathrm{LOD}=7.5$ & OM & Santos-Cortez et al., 2015 \\
\hline$A B O$ & 9 & $\begin{array}{l}\text { Histo-blood group } \\
\text { ABO system } \\
\text { transferase }\end{array}$ & Blood type & $\begin{array}{l}\text { Type O: } \\
\text { c.260insG(p.Val87_ } \\
\text { Thr88fs*) Type A }\end{array}$ & Finland & 214 probands & $\begin{array}{l}\text { Type A: }(\mathrm{OR}=2.14 \\
95 \% \mathrm{Cl}: 1.04-4.50 \\
p=0.03) \text { type } \mathrm{O} \\
(\mathrm{OR}=0.33 ; 95 \% \mathrm{Cl} \\
0.11-1.04 ; p=0.04)\end{array}$ & $\begin{array}{l}\text { RAOM/COME A } \\
\text { increases risk for } \\
\text { COME c.260insG } \\
\left.\text { (p.Val87_Thr88fs }{ }^{\star}\right) \\
\text { variant and type O } \\
\text { are protective } \\
\text { against RAOM }\end{array}$ & Wiesen et al., 2019 \\
\hline CD14 & 5 & $\begin{array}{l}\text { Cluster of } \\
\text { differentiation } 14 \\
\text { (CD14) }\end{array}$ & $\begin{array}{l}\text { Immune } \\
\text { response, } \\
\text { co-receptor of } \\
\text { TRL4 }\end{array}$ & rs2569190 & Netherlands & $\mathrm{ca}=74, \mathrm{co}=35$ & $p=0.004$ & $\mathrm{AOM}$ & Wiertsema et al., 2006a \\
\hline CPT1A & 11 & $\begin{array}{l}\text { Carnitine palmitoyl } \\
\text { transferase type } 1 \mathrm{~A} \\
\text { (CPT1A) }\end{array}$ & $\begin{array}{l}\text { Fatty acid } \\
\text { oxidation }\end{array}$ & rs80356779 & Alaska & $c a=291, c o=136$ & $p<0.001$ & $\mathrm{OM}$ & Gessner et al., 2013 \\
\hline CX3CR1 & 3 & $\begin{array}{l}\text { CX3C chemokine } \\
\text { receptor } 1\end{array}$ & $\begin{array}{l}\text { Binds to } \\
\text { chemokine }\end{array}$ & rs3732378 & USA & $\mathrm{ca}=653$ & $p=0.038$ & & Nokso-Koivisto et al., 2014 \\
\hline \multirow[t]{2}{*}{ FBXO11 } & 2 & $\begin{array}{l}\text { F-box only protein } \\
1 \text { (FBXO11) }\end{array}$ & $\begin{array}{l}\text { Protein } \\
\text { ubiquitination }\end{array}$ & $\begin{array}{l}\text { rs10182633 } \\
\text { rs12620679 } \\
\text { rs12712997 } \\
\text { rs13430439 } \\
\text { rs2710163 rs33787 } \\
\text { rs6713506 } \\
\text { rs6728843 } \\
\text { rs12712997 }\end{array}$ & Australia & $c a=253, c o=866$ & $\begin{array}{l}p=0.0009 p=0.001 \\
p=0.0002 p=0.0061 \\
p=0.0003 \\
p=6.9 \times 10^{-6} \\
p=0.0074 p=0.0061\end{array}$ & $\mathrm{AOM}$ & Rye et al., 2011 \\
\hline & & & & rs330787 & & $\begin{array}{l}\mathrm{ca}=434 \text { families } \\
\mathrm{co}=561\end{array}$ & $p=0.009 p=0.053$ & RAOM/COME & \\
\hline FCGR2A & 1 & $\begin{array}{l}\text { Fc gamma receptor } \\
\text { 11a (FCGR2A) }\end{array}$ & $\begin{array}{l}\text { Fc gamma } \\
\text { receptor, } \\
\text { immune } \\
\text { response }\end{array}$ & rs1801274 & Netherlands & $\mathrm{ca}=383$ & $p=0.03$ & OM after PV & Wiertsema et al., 2006b \\
\hline
\end{tabular}




\section{TABLE 2 | Continued}

\begin{tabular}{|c|c|c|c|c|c|c|c|c|c|}
\hline Gene & Chr: & Protein & $\begin{array}{l}\text { Function/ } \\
\text { pathway }\end{array}$ & Marker & Country & Sample size & Significance & Clinical outcome & References \\
\hline FNDC1 & 6 & $\begin{array}{l}\text { Fibronectin type III } \\
\text { domain-containing } \\
\text { protein } 1 \text { (FNDC1) }\end{array}$ & $\begin{array}{l}\text { May be an } \\
\text { activator of } G \\
\text { protein } \\
\text { signaling }\end{array}$ & rs2932989 & European & $\begin{array}{l}825 \text { cases and } \\
7,936 \text { control }\end{array}$ & $p_{\text {meta }}=2.15 \times 10^{-09}$ & $\mathrm{AOM}$ & van Ingen et al., 2016 \\
\hline FUT2 & 19 & $\begin{array}{l}\text { Galactoside } \\
\text { 2-alpha-L- } \\
\text { fucosyltransferase } \\
2 \text { (FUT2) }\end{array}$ & $\begin{array}{l}\text { Creates } \mathrm{H} \\
\text { antigen, } \\
\text { essential for the } \\
\text { formation of } \\
\text { ABO blood } \\
\text { group antigens }\end{array}$ & $\begin{array}{l}\text { rs1800022, } \\
\text { rs601338, } \\
\text { rs149356814, } \\
\text { rs602662 }\end{array}$ & $\begin{array}{l}\text { Philippines, } \\
\text { Pakistan, } \\
\text { USA }\end{array}$ & $\begin{array}{l}1 \text { Filipino } \\
\text { consanguineous } \\
\text { pedigree } 609 \\
\text { multi-ethnic families } \\
\text { and simplex case } \\
\text { subjects with OM }\end{array}$ & $\mathrm{LOD}=4.0$ & COME, AOM, OM & Santos-Cortez et al., 2018 \\
\hline IFNG & 12 & $\mathrm{IFN} \gamma$ & $\begin{array}{l}\text { Cytokines, } \\
\text { immune } \\
\text { response }\end{array}$ & rs2430561 & USA & $\mathrm{ca}=20, \mathrm{co}=57$ & $p=0.04$ & $\begin{array}{l}\text { OM with RSV } \\
\text { infection }\end{array}$ & Gentile et al., 2003 \\
\hline \multirow[t]{4}{*}{ IL10 } & 1 & $\begin{array}{l}\text { Interleukin } 10 \\
(\text { (L-10) }\end{array}$ & $\begin{array}{l}\text { Cytokines, } \\
\text { immune } \\
\text { response }\end{array}$ & $\begin{array}{l}\text { rs1554286, } \\
\text { rs1800872, } \\
\text { rs1800890, } \\
\text { rs1800893, } \\
\text { rs1800896, } \\
\text { rs3024509 }\end{array}$ & USA & 142 families & $\begin{array}{l}p(h t)=0.012 \\
p(h t)=0.039 \\
p(h t)=0.017 \\
p(h t)=0.017 \\
p(h t)=0.017, p=0.040\end{array}$ & RAOM/COME & Sale et al., 2011 \\
\hline & & & & rs1800896 & Netherlands & $\mathrm{ca}=348, \mathrm{co}=463$ & $p=0.01$ & $\begin{array}{l}\text { Protective for AOM } \\
\text { after PV }\end{array}$ & Emonts et al., 2007 \\
\hline & & & & rs1800871 & Greece & $\mathrm{ca}=96, \mathrm{c}=$ nil & $p<0.0001$ & $\mathrm{AOM}$ & llia et al., 2014 \\
\hline & & & & $\begin{array}{l}\text { rs1800896, } \\
\text { rs1800871, } \\
\text { rs1800872 }\end{array}$ & USA & $\mathrm{ca}=102, \mathrm{co}=98$ & $\begin{array}{l}p=0.005 p=0.05 \\
p=0.05\end{array}$ & $\begin{array}{l}\text { OM followed } \\
\text { RSV/RV }\end{array}$ & \\
\hline ILIA & 2 & $\begin{array}{l}\text { Interleukin I- (IL-1 } \\
\text { alpha) }\end{array}$ & $\begin{array}{l}\text { Cytokines, } \\
\text { immune } \\
\text { response }\end{array}$ & rs1800587 & Finland & $\mathrm{ca}=63, \mathrm{co}=400$ & $p=0.03$ & RAOM & Joki-Erkkila et al., 2002 \\
\hline \multirow[t]{2}{*}{ IL1B } & 2 & $\begin{array}{l}\text { Interleukin 1- } \beta \\
(\mathrm{IL}-1 \beta)\end{array}$ & $\begin{array}{l}\text { Cytokines, } \\
\text { immune } \\
\text { response }\end{array}$ & rs16944 & USA & $\mathrm{ca}=653, \mathrm{co}=$ nil & $\mathrm{OR}=1.35$ & OM (prone) & Nokso-Koivisto et al., 2014 \\
\hline & & & & rs1143634 & & $\mathrm{ca}=104, \mathrm{co}=24$ & $p=0.02$ & AOM (inflammation) & \\
\hline
\end{tabular}


TABLE 2 | Continued

\begin{tabular}{|c|c|c|c|c|c|c|c|c|c|}
\hline Gene & Chr: & Protein & $\begin{array}{l}\text { Function/ } \\
\text { pathway }\end{array}$ & Marker & Country & Sample size & Significance & Clinical outcome & References \\
\hline \multirow[t]{4}{*}{ IL6 } & 7 & Interleukin 6 (IL-6) & $\begin{array}{l}\text { Cytokines, } \\
\text { immune } \\
\text { response }\end{array}$ & rs1800795 & Netherlands & $\mathrm{ca}=347, \mathrm{co}=460$ & $\mathrm{OR}>1.45 ; p=0.02$ & $\mathrm{AOM}$ & Emonts et al., 2007 \\
\hline & & & & rs1800795 & USA & $\mathrm{ca}=68, \mathrm{co}=145$ & $p<0.01$ & RAOM & Revai et al., 2009 \\
\hline & & & & rs1800795 & USA & $\mathrm{ca}=192, \mathrm{co}=192$ & $p=0.03$ & $\mathrm{AOM}$ & Patel et al., 2006 \\
\hline & & & & rs1800795 & USA & $\mathrm{ca}=77, \mathrm{co}=80$ & $p<0.01$ & AOM & Nokso-Koivisto et al., 2014 \\
\hline MBL2 & 10 & $\begin{array}{l}\text { Mannose-binding } \\
\text { lectins (MBL) }\end{array}$ & $\begin{array}{l}\text { Immune } \\
\text { response }\end{array}$ & $\begin{array}{l}\text { rs11003125, } \\
\text { rs1800450, } \\
\text { rs1800451, } \\
\text { rs5030737, } \\
\text { rs7095891, } \\
\text { rs7096206 }\end{array}$ & Belgium & $\mathrm{ca}=17, \mathrm{co}=172$ & $\mathrm{OR}(\mathrm{ht})=2.9$ & AOM & Nuytinck et al., 2006 \\
\hline$m D N A$ & $\mathrm{mt}$ & $\mathrm{n} / \mathrm{a}$ & $\begin{array}{l}\text { Mitochondrial } \\
\text { DNA }\end{array}$ & p.Thr195Cys & $\begin{array}{l}\text { Czech } \\
\text { Republic }\end{array}$ & $\mathrm{ca}=355$ & $p=0.032$ & AOM & Sale et al., 2011 \\
\hline \multirow[t]{2}{*}{ MUC2 } & 11 & Mucin-2 & $\begin{array}{l}\text { Gel-forming } \\
\text { mucin, } \\
\text { lubrication, } \\
\text { viscoelasticity }\end{array}$ & rs7396030 & USA & 142 families & $p=0.049$ & RAOM/COME & Sale et al., 2011 \\
\hline & & & & rs7396030 & USA & 441 families & $p=0.022$ & RAOM/COME & \\
\hline MUC5AC & 11 & Mucin-5AC & $\begin{array}{l}\text { Gel-forming } \\
\text { mucin, } \\
\text { lubrication, } \\
\text { viscoelasticity }\end{array}$ & MUC5AC (intronic) & USA & $\mathrm{ca}=40, \mathrm{co}=40$ & $p=0.025$ & RAOM/COME & Ubell et al., 2010 \\
\hline \multirow[t]{3}{*}{ MUC5B } & 11 & Mucin-5B & $\begin{array}{l}\text { Gel-forming } \\
\text { mucin, } \\
\text { lubrication, } \\
\text { viscoelasticity }\end{array}$ & rs4963049 & USA & $\mathrm{ca}=102, \mathrm{co}=83$ & $p=0.033$ & COME & MacArthur et al., 2014 \\
\hline & & & & rs2075859 & USA & 142 families & $p=0.041$ & RAOM/COME & Sale et al., 2011 \\
\hline & & & & rs2735733 & USA & 142 families & $p=0.02$ & RAOM/COME & Sale et al., 2011 \\
\hline PAl1 & 7 & $\begin{array}{l}\text { Plasminogen } \\
\text { activator inhibitor-1 } \\
\text { (PAl1) }\end{array}$ & Inflammation & rs1799889 & Netherlands & $\mathrm{ca}=226, \mathrm{co}=122$ & $p=0.02$ & RAOM & Emonts et al., 2007 \\
\hline
\end{tabular}


TABLE 2 | Continued

\begin{tabular}{|c|c|c|c|c|c|c|c|c|c|}
\hline Gene & Chr: & Protein & $\begin{array}{l}\text { Function/ } \\
\text { pathway }\end{array}$ & Marker & Country & Sample size & Significance & Clinical outcome & References \\
\hline SCN1B & 19 & $\begin{array}{l}\text { Sodium channel } \\
\text { sub-unit } \beta 1 \\
\left(\mathrm{SCN}_{1} \beta\right)\end{array}$ & $\begin{array}{l}\text { lon channel } \\
\text { binding, } \\
\text { voltage-gated } \\
\text { ion channel } \\
\text { activity }\end{array}$ & rs8100085 & USA & $\mathrm{ca}=142$ families & $p=0.013$ & RAOM/COME & Sale et al., 2011 \\
\hline SFTPA1 & 10 & SFTPA1 & $\begin{array}{l}\text { Phospho- } \\
\text { lipoproteins, } \\
\text { surfactant }\end{array}$ & sa4-1a haplotype & Finland & $\mathrm{ca}=147, \mathrm{co}=278$ & $p(h t)=0.03$ & RAOM & Ramet et al., 2001 \\
\hline SFTPD & 10 & SFTPD & $\begin{array}{l}\text { Phospho- } \\
\text { lipoproteins, } \\
\text { surfactant }\end{array}$ & RS1051246 & USA & 142 families & $p=0.039$ & RAOM/COM & Sale et al., 2011 \\
\hline SLC11A1 & 2 & $\begin{array}{l}\text { Solute carrier family } \\
11 \text { member } \\
\text { (SLC11A1) }\end{array}$ & $\begin{array}{l}\text { Transporter, } \\
\text { pathogen } \\
\text { clearance }\end{array}$ & $\begin{array}{l}\text { rs2276631, } \\
\text { rs02695343, } \\
\text { rs34448891, } \\
\text { rs3731865 }\end{array}$ & Australia & $\begin{array}{l}\mathrm{ca}=531 \text { families } \\
\mathrm{co}=660\end{array}$ & $p(h t)=0.008$ & OM Proneness & Rye et al., 2013 \\
\hline SMAD2 & 18 & SMAD2 & $\begin{array}{l}\text { Transcriptional } \\
\text { modulator } \\
\text { activated by } \\
\text { TGF-beta }\end{array}$ & rs1792658 & Australia & $\begin{array}{l}\mathrm{ca}=434 \text { families } \\
\mathrm{co}=561\end{array}$ & $p=0.038$ & RAOM/COME & Rye et al., 2011 \\
\hline SMAD4 & 18 & SMAD4 & $\begin{array}{l}\text { Transcriptional } \\
\text { modulator } \\
\text { activated by } \\
\text { BMP }\end{array}$ & rs10502913 & Australia & $\begin{array}{l}c a=434 \text { families } \\
c 0=561\end{array}$ & $p=0.048$ & RAOM/COME & Rye et al., 2011 \\
\hline TGFB1 & 19 & $\begin{array}{l}\text { Transforming } \\
\text { growth factor beta } \\
1 \text { (TGF- } \beta 1 \text { ) }\end{array}$ & $\begin{array}{l}\text { Antigen } \\
\text { binding, } \\
\text { immune } \\
\text { response }\end{array}$ & rs1982073 & Greece & $\mathrm{ca}=96$ & $p=0.002$ & $\mathrm{AOM}$ & Ilia et al., 2014 \\
\hline TLR2 & 4 & $\begin{array}{l}\text { Toll-like receptor } 2 \\
\text { (TLR2) }\end{array}$ & $\begin{array}{l}\text { Inflammation, } \\
\text { initiators of } \\
\text { innate immunity } \\
\text { system }\end{array}$ & rs5743708 & Serbia & $\mathrm{ca}=85, \mathrm{co}-100$ & Significantly high & COME & Lee H.Y. et al., 2008 \\
\hline TLR4 & 9 & $\begin{array}{l}\text { Toll-like receptor } 4 \\
\text { (TLR4) }\end{array}$ & $\begin{array}{l}\text { Inflammation, } \\
\text { initiators of } \\
\text { innate immunity } \\
\text { system }\end{array}$ & $\begin{array}{l}\text { rs1800896, } \\
\text { rs1800871, } \\
\text { rs1800872 }\end{array}$ & USA & $\mathrm{ca}=172, \mathrm{co}=83$ & $\begin{array}{l}p=0.005 p=0.05 \\
p=0.05\end{array}$ & $\mathrm{AOM}$ & \|lia et al., 2014 \\
\hline
\end{tabular}


TABLE 2 | Continued

\begin{tabular}{|c|c|c|c|c|c|c|c|c|c|}
\hline Gene & Chr: & Protein & $\begin{array}{l}\text { Function/ } \\
\text { pathway }\end{array}$ & Marker & Country & Sample size & Significance & Clinical outcome & References \\
\hline & & & & $\begin{array}{l}\text { rs11788318, } \\
\text { rs4837494, } \\
\text { rs10116253, } \\
\text { rs1927914, } \\
\text { rs1554973 }\end{array}$ & USA & $\mathrm{ca}=102, \mathrm{co}=83$ & $\begin{array}{l}p=0.008, p=0.031 \\
p=0.007, p=0.023 \\
p=0.021\end{array}$ & COME & MacArthur et al., 2014 \\
\hline & & & & $\begin{array}{l}\text { rs10116253, } \\
\text { rs12377632, } \\
\text { rs22770146, } \\
\text { rs5030717 }\end{array}$ & USA & 142 families & $\begin{array}{l}p(h t)=0.025 \\
p(h t)=0.014 \\
p=0.026, p(h t)=0.017\end{array}$ & COME/RAOM & Sale et al., 2011 \\
\hline & & & & $\begin{array}{l}\text { rs5030717, } \\
\text { rs1329060, } \\
\text { rs1329057 }\end{array}$ & Finland & $\begin{array}{l}\mathrm{ca}=624, \mathrm{co}=778 \\
1,269 \text { trios } 403 \\
\text { families } \mathrm{ca}=100, \\
\mathrm{co}=104\end{array}$ & $\begin{array}{l}\mathrm{OR} 1.33, p=0.003 \mathrm{OR} \\
1.33, p=0.002 \mathrm{OR} \\
1.29, p=0.003\end{array}$ & COME/RAOM & Hafren et al., 2015 \\
\hline \multirow[t]{6}{*}{ TNFA } & 6 & $\begin{array}{l}\text { Tumor necrosis } \\
\text { factor } \alpha(T N F \alpha)\end{array}$ & $\begin{array}{l}\text { Cytokines, } \\
\text { immune } \\
\text { response }\end{array}$ & rs1800629 & USA & $c a=192, c o=192$ & $p=0.05$ & $\mathrm{AOM}$ & Emonts et al., 2007 \\
\hline & & & & & & $\mathrm{ca}=222, \mathrm{co}=120$ & & & \\
\hline & & & & rs1800750 & Netherlands & & $p=0.07$ & $\mathrm{AOM}$ & Revai et al., 2009 \\
\hline & & & & & & $\mathrm{ca}=68, \mathrm{co}=145$ & & & \\
\hline & & & & & & & $\mathrm{OR}=1.42$ & RAOM & Revai et al., 2009 \\
\hline & & & & rs1800750 & USA & & & & \\
\hline
\end{tabular}

Ca, cases; Co, controls; OR, odds ratio; $p, p$-value; $L O D$, logarithm of the odds. 
relatively common (e.g., indigenous Filipino community or Pakistani families) (Santos-Cortez et al., 2015, 2018). These studies have unveiled several novel genes and variants that confer susceptibility to familial OM (see section OM Susceptibility, Inbreeding, and Whole-Exome Sequencing): A2ML1 and FUT2 (Santos-Cortez et al., 2015, 2018).

\section{Candidate Gene-Based Studies}

Many variants in the genome have been associated with infectious diseases (Klebanov, 2018). In some instances, the clinical features and the biological mechanisms - such as immune response, inflammation, bacterial adhesion, viral infection, and mucociliary clearance - involved in those infectious diseases are compatible with the mechanisms involved during an episode of OM, thus marking the genes known for these disorders as prime candidates for OM susceptibility and recurrence. Candidate gene-based studies on OM have mainly involved genes associated with innate immunity and inflammation (Sale et al., 2011). Those studies have been performed on cohorts from all over the world including US, Finland, Australia, Netherlands, Greece, and Belgium and have identified over 100 alleles that confer susceptibility to various forms of OM (see Table 2 for the partial list of these alleles, genes, and associated clinical features). As evident from this non-exhaustive list, the identified genes belong to several different signaling cascades and developmental processes, including (a) immune response and inflammation (MBL2, TLR2, TLR4, CD14, FCGR2A, TGFB1, and PAI1) (Nuytinck et al., 2006; Wiertsema et al., 2006a,b; Emonts et al., 2007; Lee Y.C. et al., 2008; Ilia et al., 2014; Hafren et al., 2015), (b) cytokines (IL6, IL10, IL1A, IL1B, TNFA, and IFNG) (Patel et al., 2006; Alper et al., 2009; Revai et al., 2009; Ilia et al., 2014), (c) tissue clearance (SFPTA, SFTPA1, SFTPD, SLC11A1, MUC2, MUC5AC, and MUC5B) (Ramet et al., 2001; Sale et al., 2011; Rye et al., 2013; MacArthur et al., 2014), (d) transcriptional modulation (SMAD2 and SMAD4) (Rye et al., 2011), (e) chemosensitivity (CX3CR1) (Nokso-Koivisto et al., 2014), (f) protein modification (CPT1A and FBXO11) (Rye et al., 2011, 2012), and (g) channel activity (SCN1B) (Sale et al., 2011). Some of these genes, such as FBXO11, have been replicated in several independent studies, which further strengthen their role in susceptibility to OM (Segade et al., 2006; Rye et al., 2011).

\section{Genome-Wide Association Studies}

Several genome-wide association studies (GWAS) have been performed to identify new common (frequency of $75 \%$ or greater) low-risk markers $(\mathrm{OR}<1.5)$ associated with $\mathrm{OM}$ subtypes. The findings of five salient GWAS are summarized here. In the Western Australian Pregnancy Cohort (Raine) study, a cohort of 416 patients prone to OM and 1,075 normal subjects was analyzed for 2,524,817 SNPs. Although the initial analysis revealed some association, no SNP reached GWAS significance $\left(P<10^{-8}\right)$ nor could be replicated both in the Australian or US cohorts (Rye et al., 2012; Allen et al., 2014). Intriguingly, the GWAS of the Minnesota and Pittsburg cohorts identified a SNP (rs10497394 on chromosome 2) that showed a significant association (GWAS discovery $P=1.30 \times 10^{-5}$, independent otitis media population $P_{\text {meta }}=1.52 \times 10^{-8}$ ) with susceptibility to either chronic
OME or recurrent AOM (Allen et al., 2013). Finally, in a Finnish cohort (829 affected children and 2,118 randomly selected controls), the variants rs16974263 (GWAS discovery $P=1.77 \times 10^{-7}$, sub-phenotype analysis $\left.P_{\text {meta }}=2.92 \times 10^{-8}\right)$, rs268662 $\left(P=1.564 \times 10^{-6}\right)$, and $\operatorname{rs} 4150992\left(P=3.37 \times 10^{-6}\right)$ were the most significant variants associated with COME (Einarsdottir et al., 2016). In van Ingen et al. (2016) performed GWAS on a cohort of AOM children of European descent and reported a statistically significant association at 6q25.3 locus $\left(\right.$ rs2932989, $\left.P_{\text {meta }}=2.15 \times 10^{-9}\right)$. This study further demonstrated that the associated variants are correlated with the methylation status (cg05678571, $p=1.43 \times 10^{-6}$ ) and expression levels $\left(p=9.3 \times 10^{-5}\right)$ of the FNDC1 gene. Also, an independent GWAS study on more than 200,000 individuals of European ancestry reported 14 genomic regions, including FUT2 ( $p$-value: $\left.3.51 \times 10^{-30}\right)$, TBX1 $\left(1.17 \times 10^{-19}\right)$, HLA-DRB1 (rs4329147, $\left.9.55 \times 10^{-12}\right), A B O\left(3.67 \times 10^{-11}\right), \operatorname{EFEMP} 1\left(1.47 \times 10^{-10}\right)$, AUTS2 $\left(3.75 \times 10^{-9}\right)$, CDHR3 $\left(5.40 \times 10^{-9}\right), B S N\left(1.56 \times 10^{-8}\right)$, and PLG $\left(3.78 \times 10^{-8}\right)$, that were significantly associated with childhood ear infection (Tian et al., 2017), further highlighting the contribution of genetic factors responsible for OM in humans.

\section{OM Susceptibility, Inbreeding, and Whole-Exome Sequencing A2ML1}

In a large consanguineous indigenous Filipino pedigree with a high frequency of OM, Santos-Cortez et al. (2015) showed, by whole-exome and Sanger sequencing, that an 8 bp duplication in the A2ML1 gene (LOD score of 7.5) was associated with susceptibility to OM. The same duplication was found in a heterozygous or a homozygous fashion in three individuals (European American and Hispanic) of another cohort of 123 children prone to $\mathrm{OM}$ and absent in non-otitis-prone children and more than 62,000 next-generation sequences. The authors identified seven additional heterozygous $A 2 M L 1$ variants in patients of European American and Hispanic American origin with OM. A2ML1 encodes alpha-2-macroglobulin-like protein 1 (A2ML1), a protein that traps proteinases and cleaves them. A follow-up study identified 16 additional A2ML1 variants in OM subjects in indigenous Filipino and Pakistani families and US probands (Larson et al., 2019). Based on the expression in the murine mucosal epithelium of the middle ear, it has been speculated that A2ML1 may have a protective function by regulating the proteases present in the middle ear cavity and may also regulate the desquamation of epidermis (Galliano et al., 2006). Recently, by 16 S rRNA sequencing of the microbiota of the middle ear of an indigenous Filipino community prone to $\mathrm{OM}$ and segregating $A 2 M L 1$ variants, although not having a statistically significant difference between the cases and the controls, a taxonomic analysis revealed the relative abundance of the phyla Fusobacteria and Bacteroidetes and the genus Fusobacterium in A2ML1 carriers compared to non-carriers (Santos-Cortez et al., 2016).

\section{FUT2}

In the same large consanguineous indigenous Filipino pedigree with high frequency of OM, partly due to variants in $A 2 M L 1$, 
a subset of individuals were wild type for $A 2 M L 1$ but were prone to OM (Santos-Cortez et al., 2015). Further genetic analysis determined that the FUT2 variant (p.Arg202*, LOD score of 4.0) confer susceptibility to OM in those individuals (Santos-Cortez et al., 2018). Screening of DNA samples from 609 additional multi-ethnic families and simplex case subjects with OM by direct Sanger sequencing, linkage analysis, Fisher exact, and transmission disequilibrium tests revealed several other FUT2 variants (p.Arg138Cys, p.Trp154*, and p.Ala104Val) that confer susceptibility to OM (Santos-Cortez et al., 2018).

FUT enzymes are involved in the protein glycosylation pathway. FUTs transfer an L-fucose sugar derived from GDPfucose (donor substrate) to a protein (acceptor substrate). The FUT family contains 13 members (FUT1-FUT13), and many of the FUTs are essential for the synthesis of blood group antigens. FUTs are single-pass type II membrane proteins, resident to the trans-Golgi, while the catalytic domain of FUT proteins resides in the lumen of the Golgi. In humans, FUT1 and FUT2 encode galactoside 2-L-fucosyltransferase, while FUT3 encodes galactoside 3(4)-L-fucosyltransferase. FUT1 and FUT2 transfer L-fucose onto a $\beta$-D-galactosyl- $(1 \rightarrow 4)-\mathrm{N}$-acetyl- $\beta$-Dglucosaminyl derivative and create the oligosaccharide FuCalpha [(1,2)Gal-beta-], also known as $\mathrm{H}$ antigen, which is a soluble precursor essential for the final step in the soluble A and B

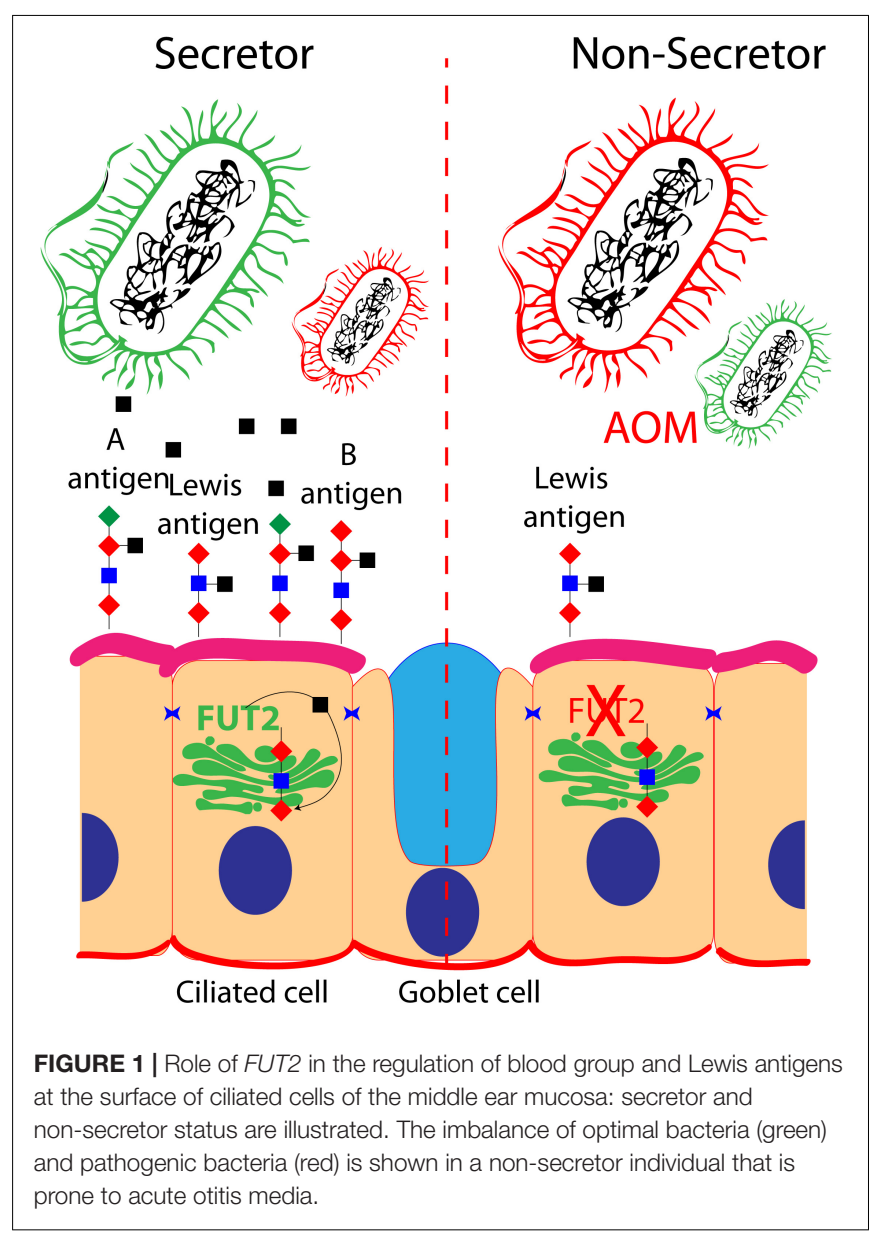

antigen synthesis pathway. FUT3 transfers L-fucose onto a $\beta$-Dgalactosyl-( $1 \rightarrow 4)$-N-acetyl- $\beta$-D-glucosaminyl derivative, or onto $\mathrm{H}$ antigen, in order to create blood group Lewis antigens.

FUT1 and FUT2 are differentially expressed in various cell types. For instance, FUT1 expression is restricted to cells of mesodermal origin (for example, erythrocytes), and FUT2 expression is being restricted to cells of endodermal origin (such as the middle ear mucosal cells). Therefore, $\mathrm{A}$ and $\mathrm{B}$ antigens will be expressed at the surface of red blood cells under the control of FUT1, while A and B antigens will be expressed at the surface of mucosal cells under the control of FUT2. Genetic variations in FUT1 and FUT2 naturally exist. Some FUT1 and FUT2 variants lead to non-functional enzymes, while certain variations in FUT2 can also lead to a reduction of its expression (Santos-Cortez et al., 2018). For instance, the FUT1 p.Tyr154Cys variant ablates the functional activity of the catalytic domain, resulting in the absence of $\mathrm{A}, \mathrm{B}$, or $\mathrm{H}$ antigens at the surface of erythrocytes (also known as the Bombay phenotype). Similarly, the FUT2 p.Trp154* variant causes absence of A, B, or $\mathrm{H}$ antigens at the surface of mucosal cells (a.k.a. non-secretor status) (Domino et al., 2001a,b). The p.Trp154* variant of FUT2 is also

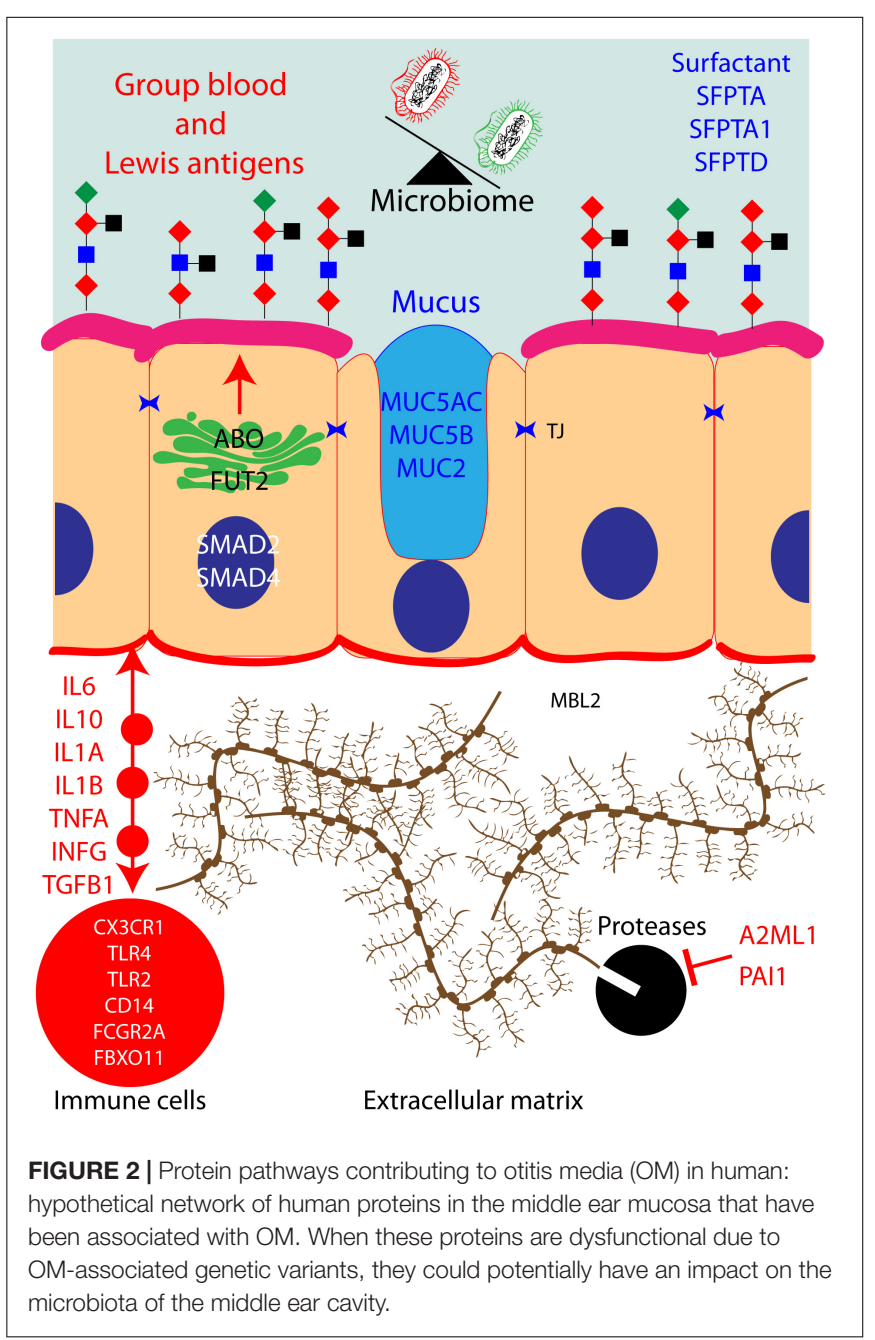


responsible for the non-secretor phenotype in European and African populations (47 and $42 \%$, respectively).

$\mathrm{A}, \mathrm{B}$, and $\mathrm{H}$ and Lewis antigens are known to serve as an energy source while also regulating the adhesion of bacteria to the cell surface (Ewald and Sumner, 2018; Figure 1). Intuitively, the different blood group antigens and their quantity at the surface of the cells of the mucosal epithelium of the middle ear would have an impact on the microbiota present in the middle ear cavity, and various blood types have been associated with OM (Wiesen et al., 2019). For instance, studies in a Finnish cohort reported a protective effect of blood type $\mathrm{O}$ against recurrent AOM, whereas blood type A was associated with increased risk for chronic OME (Wiesen et al., 2019). When tested in vitro, the four FUT2 variants associated with OM (p.Ala104Val, p.Arg138Cys, p.Trp154*, and p.Arg202*) reduced the A antigen levels, while the two nonsense variants also reduced the FUT2 protein levels. Moreover, Fut2 is transiently upregulated in the murine middle ear after inoculation with the non-typeable H. influenza (SantosCortez et al., 2018). It is speculated that the OM-associated FUT2 variants are modifying the middle ear microbiome through the regulation of $\mathrm{A}$ antigen levels in the middle ear mucosa, thus conferring susceptibility to OM (Santos-Cortez et al., 2018).

While the microbial richness, structure, and composition differences were not statistically significant between the control individuals and the individuals prone to $\mathrm{OM}$ in the indigenous Filipino community segregating FUT2 p.Arg202* variant, the individuals from a Colorado cohort prone to $\mathrm{OM}$ and carrier for the FUT2 p.Trp $154^{*}$ variant had a relatively high abundance of Lactobacillales and Gamma-proteobacteria in their middle ears (Santos-Cortez et al., 2018). Further studies in animal models are necessary to fully understand the FUT2associated OM mechanism.

\section{CONCLUSION}

The current genetic and molecular data revealed the association of OM with deficits in each of the following mechanisms: (1) development of the middle ear cavity and Eustachian tube, (2) immune response, (3) bacterial adhesion and viral infection, (4) regulation of the extracellular matrix, and (5) clearance of the middle ear.

In Figure 2, we have attempted to build a network that encompasses most of the known human proteins that have been

\section{REFERENCES}

Abrahams, S. W., and Labbok, M. H. (2011). Breastfeeding and otitis media: a review of recent evidence. Curr. Allergy Asthma Rep. 11, 508-512. doi: 10.1007/ s11882-011-0218-3

Allen, E. K., Chen, W. M., Weeks, D. E., Chen, F., Hou, X., Mattos, J. L., et al. (2013). A genome-wide association study of chronic otitis media with effusion and recurrent otitis media identifies a novel susceptibility locus on chromosome 2. J. Assoc. Res. Otolaryngol. 14, 791-800. doi: 10.1007/s10162-0130411-2

Allen, E. K., Manichaikul, A., Chen, W. M., Rich, S. S., Daly, K. A., Sale, M. M., et al. (2014). Evaluation of replication of variants associated with genetic risk of otitis media. PLoS One 9:e104212. doi: 10.1371/journal.pone.0104212 associated with $\mathrm{OM}$ and our hypothesis about the potential impact on the microbiome of the middle ear cavity when these proteins are dysfunctional due to $\mathrm{OM}$-associated genetic variants. Briefly, ABO and FUT2 are localized in the Golgi apparatus of the cells of the middle ear mucosa; these two proteins together create blood group Lewis antigens, potential sources of energy for microbiome. These antigens also provide an adhesion platform for the microbiota. Similarly, goblet cells secrete MUC5AC, MUC5B, MUC2 SFPTA, SFPTA1, and SFPTD to form mucus and surfactants in the middle ear cavity. Bacteria are present in these secretions and are cleared from the middle ear cavity by ciliated cells in order to maintain a healthy microbiome. Cells from the middle ear also secrete interleukins, chemokines, interferons, and necrosis and growth factors in order to recruit immune cells in the extracellular matrix. These cells fight infection and eliminate dead cells. During the inflammatory stage, the extracellular matrix is remodeled by proteases to allow immune cell infiltration. Those proteases are regulated and inhibited by A2ML1 and PAI1. A pathogenic genetic variation in any of those genes would eventually lead to middle ear infection and OM.

Future studies of the enrichment of certain microbiota in individuals with specific genetic variants may eventually help in identifying patients before chronic OM sets in or in devising a patient-specific treatment paradigm in the future.

\section{AUTHOR CONTRIBUTIONS}

AG, SA, AI, IA, SR, and ZA wrote the draft and finalized it.

\section{FUNDING}

Research in the Ahmed Laboratory was supported by the National Institutes of Health/NIDCD R01DC012564 and R01DC016295.

\section{ACKNOWLEDGMENTS}

We thank Ms. Bernadine Monari, Dimitria Gomes, and Dr. Elodie Richard for their critiques of the manuscript.

Alper, C. M., Winther, B., Hendley, J. O., and Doyle, W. J. (2009). Cytokine polymorphisms predict the frequency of otitis media as a complication of rhinovirus and RSV infections in children. Eur. Arch. Otorhinolaryngol. 266, 199-205. doi: 10.1007/s00405-008-0729-2

Austeng, M. E., Akre, H., Øverland, B., Abdelnoor, M., Falkenberg, E. S., and Kværner, K. J. (2013). Otitis media with effusion in children with in Down syndrome. Int. J. Pediatr. Otorhinolaryngol. 77, 1329-1332. doi: 10.1016/j.ijporl. 2013.05.027

Ayon-Nunez, D. A., Fragoso, G., Bobes, R. J., and Laclette, J. (2018). Plasminogenbinding proteins as an evasion mechanism of the host's innate immunity in infectious diseases*. Biosci. Rep. 38,

Azar, A., Piccinelli, C., Brown, H., Headon, D., and Cheeseman, M. (2016). Ectodysplasin signalling deficiency in mouse models of hypohidrotic 
ectodermal dysplasia leads to middle ear and nasal pathology. Hum. Mol. Genet. 25, 3564-3577. doi: 10.1093/hmg/ddw202

Bhutta, M. F. (2015). Evolution and otitis media: a review, and a model to explain high prevalence in indigenous populations. Hum. Biol. 87, 92-108. doi: 10. 13110/humanbiology.87.2.0092

Bhutta, M. F., Cheeseman, M. T., and Brown, S. D. (2014). Myringotomy in the Junbo mouse model of chronic otitis media alleviates inflammation and cellular hypoxia. Laryngoscope 124, E377-E383. doi: 10.1002/lary.24698

Bhutta, M. F., Lambie, J., Hobson, L., Goel, A., Hafrén, L., Einarsdottir, E., et al. (2017). A mouse-to-man candidate gene study identifies association of chronic otitis media with the loci TGIF1 and FBXO11. Sci. Rep. 7:12496. doi: 10.1038/ s41598-017-12784-8

Bois, E., Nassar, M., Zenaty, D., Léger, J., Van Den Abbeele, T., and Teissier, N. (2018). Otologic disorders in Turner syndrome. Eur. Ann. Otorhinolaryngol. Head Neck Dis. 135, 21-24. doi: 10.1016/j.anorl.2017.08.006

Carpinelli, M. R., Kruse, E. A., Arhatari, B. D., Debrincat, M. A., Ogier, J. M., Bories, J. C., et al. (2015). Mice haploinsufficient for Ets1 and Fli1 display middle ear abnormalities and model aspects of jacobsen syndrome. Am. J. Pathol. 185, 1867-1876. doi: 10.1016/j.ajpath.2015.03.026

Casselbrant, M. L., Mandel, E. M., Fall, P. A., Rockette, H. E., Kurs-Lasky, M., Bluestone, C. D., et al. (1999). The heritability of otitis media: a twin and triplet study. JAMA 282, 2125-2130.

Cheeseman, M. T., Tyrer, H. E., Williams, D., Hough, T. A., Pathak, P., Romero, M. R., et al. (2011). HIF-VEGF pathways are critical for chronic otitis media in Junbo and Jeff mouse mutants. PLoS Genet. 7:e1002336. doi: 10.1371/journal. pgen. 1002336

Chen, J., Ingham, N., Clare, S., Raisen, C., Vancollie, V. E., Ismail, O., et al. (2013). Mcph1-deficient mice reveal a role for MCPH1 in otitis media. PLoS One 8:e58156. doi: 10.1371/journal.pone.0058156

Clements, D. A. (1968). Otitis media and hearing loss in a small aboriginal community. Med. J. Aust. 1, 665-667. doi: 10.5694/j.1326-5377.1968.tb28789.x

Crompton, M., Purnell, T., Tyrer, H. E., Parker, A., Ball, G., Hardisty-Hughes, R. E., et al. (2017). A mutation in Nischarin causes otitis media via LIMK1 and NF-kappaB pathways. PLoS Genet. 13:e1006969. doi: 10.1371/journal.pgen. 1006969

Del-Pozo, J., MacIntyre, N., Azar, A., Glover, J., Milne, E., and Cheeseman, M. (2019). Chronic otitis media is initiated by a bulla cavitation defect in the FBXO11 mouse model*. Dis. Model Mech. 12, doi: 10.1242/dmm.038315

Depreux, F. F., Darrow, K., Conner, D. A., Eavey, R. D., Liberman, M. C., Seidman, C. E., et al. (2008). Eya4-deficient mice are a model for heritable otitis media. J. Clin. Invest. 118, 651-658. doi: 10.1172/JCI32899

Domino, S. E., Zhang, L., and Lowe, J. B. (2001b). Molecular cloning, genomic mapping, and expression of two secretor blood group alpha $(1,2)$ fucosyltransferase genes differentially regulated in mouse uterine epithelium and gastrointestinal tract. J. Biol. Chem. 276, 23748-23756. doi: $10.1074 /$ jbc.m100735200

Domino, S. E., Zhang, L., Gillespie, P. J., Saunders, T. L., and Lowe, J. B. (2001a). Deficiency of reproductive tract alpha(1,2)fucosylated glycans and normal fertility in mice with targeted deletions of the FUT1 or FUT2 alpha(1,2)fucosyltransferase locus. Mol. Cell Biol. 21, 8336-8345. doi: 10.1128/ mcb.21.24.8336-8345.2001

Einarsdottir, E., Hafrén, L., Leinonen, E., Bhutta, M. F., Kentala, E., Kere, J., et al. (2016). Genome-wide association analysis reveals variants on chromosome 19 that contribute to childhood risk of chronic otitis media with effusion. Sci. Rep. 6:33240. doi: 10.1038/srep33240

Emonts, M., Veenhoven, R. H., Wiertsema, S. P., Houwing-Duistermaat, J. J., Walraven, V., de Groot, R., et al. (2007). Genetic polymorphisms in immunoresponse genes TNFA, IL6, IL10, and TLR4 are associated with recurrent acute otitis media. Pediatrics 120, 814-823. doi: 10.1542/peds.20070524

Eriksson, P. O., Li, J., Ny, T., and Hellström, S. (2006). Spontaneous development of otitis media in plasminogen-deficient mice. Int. J. Med. Microbiol. 296, 501-509. doi: $10.1016 /$ j.ijmm.2006.04.002

Ewald, D. R., and Sumner, S. C. J. (2018). Human microbiota, blood group antigens, and disease. Wiley Interdiscip. Rev. Syst. Biol. Med. 10:e1413. doi: 10.1002/wsbm. 1413

Fireman, P. (1997). Otitis media and eustachian tube dysfunction: connection to allergic rhinitis. J. Allergy Clin. Immunol. 99, S787-S797.
Galliano, M. F., Toulza, E., Gallinaro, H., Jonca, N., Ishida-Yamamoto, A., Serre, G., et al. (2006). A novel protease inhibitor of the alpha2-macroglobulin family expressed in the human epidermis. J. Biol. Chem. 281, 5780-5789. doi: 10.1074/ jbc.m508017200

Gawron, W., Wikiera, B., Rostkowska-Nadolska, B., Orendorz-Frączkowska, K., and Noczyńska, A. (2008). Evaluation of hearing organ in patients with Turner syndrome. Int. J. Pediatr. Otorhinolaryngol. 72, 575-579. doi: 10.1016/j.ijporl. 2008.01.021

Gentile, D. A., Doyle, W. J., Zeevi, A., Howe-Adams, J., Kapadia, S., Trecki, J., et al. (2003). Cytokine gene polymorphisms moderate illness severity in infants with respiratory syncytial virus infection. Hum. Immunol. 64, 338-344. doi: 10.1016/s0198-8859(02)00827-3

Gessner, B. D., Gillingham, M. B., Wood, T., and Koeller, D. M. (2013). Association of a genetic variant of carnitine palmitoyltransferase $1 \mathrm{~A}$ with infections in Alaska Native children. J. Pediatr. 163, 1716-1721. doi: 10.1016/j.jpeds.2013.07. 010

Giebink, G. S., and Canafax, D. M. (1991). Antimicrobial treatment of otitis media. Semin. Respir. Infect. 6, 85-93.

Hafren, L., Einarsdottir, E., Kentala, E., Hammarén-Malmi, S., Bhutta, M. F., MacArthur, C. J., et al. (2015). Predisposition to childhood otitis media and genetic polymorphisms within the toll-like receptor 4 (TLR4) locus. PLoS One 10:e0132551. doi: 10.1371/journal.pone.0132551

Han, F., Yu, H., Li, P., Zhang, J., Tian, C., Li, H., et al. (2012). Mutation in Phex gene predisposes BALB/c-Phex(Hyp-Duk)/Y mice to otitis media. PLoS One 7:e43010. doi: 10.1371/journal.pone.0043010

Hardisty, R. E., Erven, A., Logan, K., Morse, S., Guionaud, S., Sancho-Oliver, S., et al. (2003). The deaf mouse mutant Jeff (Jf) is a single gene model of otitis media. J. Assoc. Res. Otolaryngol. 4, 130-138. doi: 10.1007/s10162-002-3015-9

Hardisty-Hughes, R. E., Tateossian, H., Morse, S. A., Romero, M. R., Middleton, A., Tymowska-Lalanne, Z., et al. (2006). A mutation in the F-box gene, Fbxo11, causes otitis media in the Jeff mouse. Hum. Mol. Genet. 15, 3273-3279. doi: $10.1093 / \mathrm{hmg} / \mathrm{ddl} 403$

Hernandez, M., Leichtle, A., Pak, K., Ebmeyer, J., Euteneuer, S., Obonyo, M., et al. (2008). Myeloid differentiation primary response gene 88 is required for the resolution of otitis media. J. Infect. Dis. 198, 1862-1869. doi: 10.1086/593213

Ilia, S., Goulielmos, G. N., Samonis, G., and Galanakis, E. (2014). Polymorphisms in IL-6, IL-10, TNF-alpha, IFN-gamma and TGF-beta1 genes and susceptibility to acute otitis media in early infancy. Pediatr. Infect. Dis. J. 33, 518-521. doi: 10.1097/INF.0000000000000229

Joki-Erkkila, V. P., Puhakka, H., and Hurme, M. (2002). Cytokine gene polymorphism in recurrent acute otitis media. Arch. Otolaryngol. Head Neck Surg. 128, 17-20.

Kalm, O., Johnson, U., and Prellner, K. (1994). HLA frequency in patients with chronic secretory otitis media. Int. J. Pediatr. Otorhinolaryngol. 30, 151-157. doi: 10.1016/0165-5876(94)90198-8

Kalm, O., Johnson, U., Prellner, K., and Ninn, K. (1991). HLA frequency in patients with recurrent acute otitis media. Arch. Otolaryngol. Head Neck Surg. 117, 1296-1299. doi: 10.1001/archotol.1991.01870230112019

Kerschner, J. E., Hong, W., Taylor, S. R., Kerschner, J. A., Khampang, P., Wrege, K. C., et al. (2013). A novel model of spontaneous otitis media with effusion (OME) in the Oxgr1 knock-out mouse. Int. J. Pediatr. Otorhinolaryngol. 77, 79-84. doi: 10.1016/j.ijporl.2012.09.037

Klebanov, N. (2018). Genetic predisposition to infectious disease. Cureus 10:e3210. doi: $10.7759 /$ cureus. 3210

Larson, E. D., Magno, J. P. M., Steritz, M. J., Llanes, E. G. D. V., Cardwell, J., Pedro, M., et al. (2019). A2ML1 and otitis media: novel variants, differential expression, and relevant pathways. Hum. Mutat. 40, 1156-1171. doi: 10.1002/humu.23769

Leach, A. J., Wigger, C., Beissbarth, J., Woltring, D., Andrews, R., Chatfield, M. D., et al. (2016). General health, otitis media, nasopharyngeal carriage and middle ear microbiology in Northern Territory Aboriginal children vaccinated during consecutive periods of 10 -valent or 13-valent pneumococcal conjugate vaccines. Int. J. Pediatr. Otorhinolaryngol. 86, 224-232. doi: 10.1016/j.ijporl.2016.05.011

Lee, H. Y., Takeshita, T., Shimada, J., Akopyan, A., Woo, J. I., Pan, H., et al. (2008). Induction of beta defensin 2 by NTHi requires TLR2 mediated MyD88 and IRAK-TRAF6-p38MAPK signaling pathway in human middle ear epithelial cells. BMC Infect. Dis. 8:87. doi: 10.1186/1471-2334-8-87

Lee, Y. C., Kim, C., Shim, J. S., Byun, J. Y., Park, M. S., Cha, C. I., et al. (2008). Toll-like receptors 2 and 4 and their mutations in patients with otitis media and 
middle ear effusion. Clin. Exp. Otorhinolaryngol. 1, 189-195. doi: 10.3342/ceo. 2008.1.4.189

Leichtle, A., Hernandez, M., Ebmeyer, J., Yamasaki, K., Lai, Y., Radek, K., et al. (2010). CC chemokine ligand 3 overcomes the bacteriocidal and phagocytic defect of macrophages and hastens recovery from experimental otitis media in TNF-/- mice. J. Immunol. 184, 3087-3097. doi: 10.4049/jimmunol.0901167

Li, Q., Li, Y. X., Stahl, G. L., Thurman, J. M., He, Y., and Tong, H. H. (2011). Essential role of factor B of the alternative complement pathway in complement activation and opsonophagocytosis during acute pneumococcal otitis media in mice. Infect. Immun. 79, 2578-2585. doi: 10.1128/IAI.00168-11

Li, X., Xu, L., Li, J., Li, B., Bai, X., Strauss, J. F. I. I. I., et al. (2014). Otitis media in sperm-associated antigen 6 (Spag6)-deficient mice. PLoS One 9:e112879. doi: 10.1371/journal.pone.0112879

Lubianca Neto, J. F., Hemb, L., and Silva, D. B. (2006). Systematic literature review of modifiable risk factors for recurrent acute otitis media in childhood. J. Pediatr. 82, 87-96. doi: 10.2223/jped.1453

MacArthur, C. J., Wilmot, B., Wang, L., Schuller, M., Lighthall, J., and Trune, D. (2014). Genetic susceptibility to chronic otitis media with effusion: candidate gene single nucleotide polymorphisms. Laryngoscope 124, 1229-1235. doi: 10. 1002/lary.24349

Maguire, S., Estabel, J., Ingham, N., Pearson, S., Ryder, E., Carragher, D. M., et al. (2014). Targeting of Slc25a21 is associated with orofacial defects and otitis media due to disrupted expression of a neighbouring gene. PLoS One 9:e91807. doi: 10.1371/journal.pone.0091807

Mitchell, C. R., Kempton, J. B., Scott-Tyler, B., and Trune, D. R. (1997). Otitis media incidence and impact on the auditory brain stem response in lipopolysaccharide-nonresponsive $\mathrm{C} 3 \mathrm{H} / \mathrm{HeJ}$ mice. Otolaryngol. Head Neck Surg. 117, 459-464. doi: 10.1016/s0194-5998(97)70014-7

Monasta, L., Ronfani, L., Marchetti, F., Montico, M., Vecchi Brumatti, L., Bavcar, A., et al. (2012). Burden of disease caused by otitis media: systematic review and global estimates. PLoS One 7:e36226.

Morris, P. S. (1998). A systematic review of clinical research addressing the prevalence, aetiology, diagnosis, prognosis and therapy of otitis media in Australian Aboriginal children. J. Paediatr. Child Health 34, 487-497. doi: 10.1046/j.1440-1754.1998.00299.x

Mortensen, E. H., Lildholdt, T., Gammelgård, N. P., and Christensen, P. H. (1983). Distribution of ABO blood groups in secretory otitis media and cholesteatoma. Clin. Otolaryngol. Allied Sci. 8, 263-265. doi: 10.1111/j.13652273.1983.tb01439.x

Mulay, A., Hood, D. W., Williams, D., Russell, C., Brown, S. D. M., Bingle, L., et al. (2018). Loss of the homeostatic protein BPIFA1, leads to exacerbation of otitis media severity in the Junbo mouse model. Sci. Rep. 8:3128. doi: 10.1038/s41598018-21166-7

Musa, M., Wilson, K., Sun, L., Mulay, A., Bingle, L., Marriott, H. M., et al. (2012). Differential localisation of BPIFA1 (SPLUNC1) and BPIFB1 (LPLUNC1) in the nasal and oral cavities of mice. Cell Tissue Res. 350, 455-464. doi: 10.1007/ s00441-012-1490-9

Nakamura, Y., Komori, M., Yamakawa, K., Hamajima, Y., Suzuki, M., Kim, Y., et al. (2013). Math1, retinoic acid, and TNF-alpha synergistically promote the differentiation of mucous cells in mouse middle ear epithelial cells in vitro. Pediatr. Res. 74, 259-265. doi: 10.1038/pr.2013.103

Nokso-Koivisto, J., Chonmaitree, T., Jennings, K., Matalon, R., Block, S., and Patel, J. A. (2014). Polymorphisms of immunity genes and susceptibility to otitis media in children. PLoS One 9:e93930. doi: 10.1371/journal.pone.0093930

Nokso-Koivisto, J., Marom, T., and Chonmaitree, T. (2015). Importance of viruses in acute otitis media. Curr. Opin. Pediatr. 27, 110-115. doi: 10.1097/MOP. 0000000000000184

Norhayati, M. N., Ho, J. J., and Azman, M. Y. (2017). Influenza vaccines for preventing acute otitis media in infants and children. Cochrane Database Syst. Rev. 10:CD010089. doi: 10.1002/14651858.CD010089.pub3

Nuytinck, L., De Meester, E., and Van Thielen, M. (2006). Govaerts Role of mannose-binding lectin (MBL2) genotyping in predicting the risk of recurrent otitis media (rOM). Adv. Exp. Med. Biol. 586, 281-290. doi: 10.1007/0-38734134-x_19

Parkinson, N., Hardisty-Hughes, R. E., Tateossian, H., Tsai, H. T., Brooker, D., Morse, S., et al. (2006). Mutation at the Evil locus in Junbo mice causes susceptibility to otitis media. PLoS Genet. 2:e149. doi: 10.1371/journal.pgen. 0020149
Patel, J. A., Nair, S., Revai, K., Grady, J., Saeed, K., Matalon, R., et al. (2006). Association of proinflammatory cytokine gene polymorphisms with susceptibility to otitis media. Pediatrics 118, 2273-2279. doi: 10.1542/peds. 2006-0764

Ram, G., and Chinen, J. (2011). Infections and immunodeficiency in Down syndrome. Clin. Exp. Immunol. 164, 9-16. doi: 10.1111/j.1365-2249.2011. 04335.x

Ramet, M., Löfgren, J., Alho, O. P., and Hallman, M. (2001). Surfactant proteinA gene locus associated with recurrent otitis media. J. Pediatr. 138, 266-268. doi: $10.1067 / \mathrm{mpd} .2001 .110133$

Raymond, B. B., and Djordjevic, S. (2015). Exploitation of plasmin(ogen) by bacterial pathogens of veterinary significance. Vet. Microbiol. 178, 1-13. doi: 10.1016/j.vetmic.2015.04.008

Revai, K., Patel, J. A., Grady, J. J., Nair, S., Matalon, R., and Chonmaitree, T. (2009). Association between cytokine gene polymorphisms and risk for upper respiratory tract infection and acute otitis media. Clin. Infect. Dis. 49, 257-261. doi: $10.1086 / 599833$

Roberts, J. E., Rosenfeld, R. M., and Zeisel, S. A. (2004). Otitis media and speech and language: a meta-analysis of prospective studies. Pediatrics $113(3 \mathrm{Pt} \mathrm{1}$ ), e238-e248. doi: 10.1542/peds.113.3.e238

Rye, M. S., Warrington, N. M., Scaman, E. S., Vijayasekaran, S., Coates, H. L., Anderson, D., et al. (2012). Genome-wide association study to identify the genetic determinants of otitis media susceptibility in childhood. PLoS One 7:e48215. doi: 10.1371/journal.pone.0048215

Rye, M. S., Wiertsema, S. P., Scaman, E. S., Oommen, J., Sun, W., Francis, R. W., et al. (2011). FBXO11, a regulator of the TGFbeta pathway, is associated with severe otitis media in Western Australian children. Genes Immun. 12, 352-359. doi: 10.1038/gene.2011.2

Rye, M. S., Wiertsema, S. P., Scaman, E. S., Thornton, R., Francis, R. W., Vijayasekaran, S., et al. (2013). Genetic and functional evidence for a role for SLC11A1 in susceptibility to otitis media in early childhood in a Western Australian population. Infect. Genet. Evol. 16, 411-418. doi: 10.1016/j.meegid. 2013.03.023

Sale, M. M., Chen, W. M., Weeks, D. E., Mychaleckyj, J. C., Hou, X., Marion, M., et al. (2011). Evaluation of 15 functional candidate genes for association with chronic otitis media with effusion and/or recurrent otitis media (COME/ROM). PLoS One 6:e22297. doi: 10.1371/journal.pone.002 2297

Santos-Cortez, R. L. P., Chiong, C. M., Frank, D. N., Ryan, A. F., Giese, A. P. J., Bootpetch Roberts, T., et al. (2018). FUT2 variants confer susceptibility to familial otitis media. Am. J. Hum. Genet. 103, 679-690. doi: 10.1016/j.ajhg.2018. 09.010

Santos-Cortez, R. L., Chiong, C. M., Reyes-Quintos, M. R., Tantoco, M. L., Wang, X., Acharya, A., et al. (2015). Rare A2ML1 variants confer susceptibility to otitis media. Nat. Genet. 47, 917-920. doi: 10.1038/ng.3347

Santos-Cortez, R. L., Hutchinson, D. S., Ajami, N. J., Reyes-Quintos, M. R., Tantoco, M. L., Labra, P. J., et al. (2016). Middle ear microbiome differences in indigenous Filipinos with chronic otitis media due to a duplication in the A2ML1 gene. Infect. Dis. Poverty 5, 97.

Sculerati, N., Ledesma-Medina, J., Finegold, D. N., and Stool, S. E. (1990). Otitis media and hearing loss in Turner syndrome. Arch. Otolaryngol. Head Neck Surg. 116, 704-707.

Segade, F., Daly, K. A., Allred, D., Hicks, P. J., Cox, M., Brown, M., et al. (2006). Association of the FBXO11 gene with chronic otitis media with effusion and recurrent otitis media: the Minnesota COME/ROM family study. Arch. Otolaryngol. Head Neck Surg. 132, 729-733.

Shibahara, Y., and Sando, I. (1989). Congenital anomalies of the eustachian tube in Down syndrome. Histopathologic case report. Ann. Otol. Rhinol. Laryngol. $98(7$ Pt 1), 543-547. doi: $10.1177 / 00034894890980$ 0709

Shimada, J., Moon, S. K., Lee, H. Y., Takeshita, T., Pan, H., Woo, J. I., et al. (2008). Lysozyme M deficiency leads to an increased susceptibility to Streptococcus pneumoniae-induced otitis media. BMC Infect. Dis. 8:134. doi: 10.1186/14712334-8-134

Shin, S. G., Koh, S. H., Woo, C. H., and Lim, J. H. (2014). PAI-1 inhibits development of chronic otitis media and tympanosclerosis in a mouse model of otitis media. Acta Otolaryngol. 134, 1231-1238. doi: 10.3109/00016489.2014. 940554 
Suzukawa, K., Tomlin, J., Pak, K., Chavez, E., Kurabi, A., Baird, A., et al. (2014). A mouse model of otitis media identifies HB-EGF as a mediator of inflammationinduced mucosal proliferation. PLoS One 9:e102739. doi: 10.1371/journal.pone. 0102739

Swanson, J. A., and Hoecker, J. L. (1996). Concise review for primary-care physicians. Mayo.Clin Proc. 71, 179-183.

Tateossian, H., Morse, S., Parker, A., Mburu, P., Warr, N., Acevedo-Arozena, A., et al. (2013). Otitis media in the Tgif knockout mouse implicates TGFbeta signalling in chronic middle ear inflammatory disease. Hum. Mol. Genet. 22, 2553-2565. doi: 10.1093/hmg/ddt103

Tefs, K., Gueorguieva, M., Klammt, J., Allen, C. M., Aktas, D., Anlar, F. Y., et al. (2006). Molecular and clinical spectrum of type I plasminogen deficiency: a series of 50 patients. Blood 108, 3021-3026. doi: 10.1182/blood-2006-04017350

Thomas, S. H., Meyers, A. D., Allen, G. C., and Thrasher, R. D. (2004). Otitis media with effusion. Pediatrics 113, 1412-1429.

Tian, C., Harris, B. S., and Johnson, K. R. (2016). Ectopic mineralization and conductive hearing loss in enpplasj mutant mice, a new model for otitis media and tympanosclerosis. PLoS One 11:e0168159. doi: 10.1371/journal.pone. 0168159

Tian, C., Hromatka, B. S., Kiefer, A. K., Eriksson, N., Noble, S. M., Tung, J. Y., et al. (2017). Genome-wide association and HLA region fine-mapping studies identify susceptibility loci for multiple common infections. Nat. Commun. 8:599. doi: 10.1038/s41467-017-00257-5

Tian, C., Yu, H., Yang, B., Han, F., Zheng, Y., Bartels, C. F., et al. (2012). Otitis media in a new mouse model for CHARGE syndrome with a deletion in the Chd7 gene. PLoS One 7:e34944. doi: 10.1371/journal.pone.0034944

Ubell, M. L., Khampang, A., and Kerschner, J. E. (2010). Mucin gene polymorphisms in otitis media patients. Laryngoscope 120, 132-138. doi: 10. 1002/lary.20688

van Ingen, G., Li, J., Goedegebure, A., Pandey, R., Li, Y. R., March, M. E., et al. (2016). Genome-wide association study for acute otitis media in children identifies FNDC1 as disease contributing gene. Nat. Commun. 7:12792. doi: $10.1038 /$ ncomms 12792

Wiertsema, S. P., Hogenkamp, A., Wiertsema, S. P., Harthoorn, L. F., Loonstra, R., Hartog, A., et al. (2006a). Association of CD14 promoter polymorphism with otitis media and pneumococcal vaccine responses. Clin. Vaccine Immunol. 13, 892-897. doi: 10.1128/cvi.00100-06

Wiertsema, S. P., Veenhoven, R. H., Walraven, V., Uiterwaal, C. S., Schilder, A. G., Rijkers, G. T., et al. (2006b). Pneumococcal vaccine efficacy for mucosal pneumococcal infections depends on Fcgamma receptor IIa polymorphism. Vaccine 24, 792-797. doi: 10.1016/j.vaccine.2005.08.029

Wiesen, B. M., Hafrén, L., Einarsdottir, E., Kere, J., Mattila, P. S., Santos-Cortez R. L., et al. (2019). ABO genotype and blood type are associated with otitis media. Genet. Test Mol. Biomarkers 23, 823-827. doi: 10.1089/gtmb.2019. 0135

Woo, J. I., Pan, H., Oh, S., Lim, D. J., and Moon, S. K. (2010). Spiral ligament fibrocyte-derived MCP-1/CCL2 contributes to inner ear inflammation secondary to nontypeable H. influenzae-induced otitis media. BMC Infect. Dis. 10:314. doi: 10.1186/1471-2334-10-314

Yang, B., Tian, C., Zhang, Z. G., Han, F. C., Azem, R., Yu, H., et al. (2011). Sh3pxd2b mice are a model for craniofacial dysmorphology and otitis media. PLoS One 6:e22622. doi: 10.1371/journal.pone.0022622

Yao, W., Frie, M., Pan, J., Pak, K., Webster, N., Wasserman, S. I., et al. (2014). CJun N-terminal kinase (JNK) isoforms play differing roles in otitis media. BMC Immunol. 15:46. doi: 10.1186/s12865-014-0046-Z

Zhang, Y., Yu, H., Xu, M., Han, F., Tian, C., Kim, S., et al. (2012). Pathological features in the LmnaDhe/+ mutant mouse provide a novel model of human otitis media and laminopathies. Am. J. Pathol. 181, 761-774. doi: 10.1016/j. ajpath.2012.05.031

Conflict of Interest: The authors declare that the research was conducted in the absence of any commercial or financial relationships that could be construed as a potential conflict of interest.

Copyright (c) 2020 Giese, Ali, Isaiah, Aziz, Riazuddin and Ahmed. This is an openaccess article distributed under the terms of the Creative Commons Attribution License (CC BY). The use, distribution or reproduction in other forums is permitted, provided the original author(s) and the copyright owner(s) are credited and that the original publication in this journal is cited, in accordance with accepted academic practice. No use, distribution or reproduction is permitted which does not comply with these terms. 